\title{
Invisible Wounds
}

\section{Mental Health and Cognitive Care Needs of America's Returning Veterans}

RAND RESEARCH AREAS

THE ARTS

CHILD POLICY

CIVIL JUSTICE

EDUCATION

ENERGY AND ENVIRONMENT

HEALTH AND HEALTH CARE

INTERNATIONAL AFFAIRS

NATIONAL SECURITY

POPULATION AND AGING

PUBLIC SAFETY

SCIENCE AND TECHNOLOGY

SUBSTANCE ABUSE

TERRORISM AND

HOMELAND SECURITY

TRANSPORTATION AND

INFRASTRUCTURE

WORKFORCE AND WORKPLACE

This product is part of the RAND Corporation research brief series. RAND research briefs present policy-oriented summaries of published, peer-reviewed documents.

Corporate Headquarters 1776 Main Street P.O. Box 2138 Santa Monica, California 90407-2138 TEL 310.393 .0411 FAX 310.393 .4818

(c) RAND 2008
S ince October 2001, approximately 1.64 million U.S. troops have deployed to support operations in Afghanistan and Iraq. Many have been exposed for prolonged periods to combat-related stress or traumatic events. Safeguarding the mental health of these servicemembers and veterans is an important part of ensuring the future readiness of our military force and compensating and honoring those who have served our nation. In the wake of recent reports and media attention, public concern about the care of the war wounded is high. In response, several task forces, independent review groups, and a Presidential Commission have examined the care of the war wounded and recommended improvements. Policy changes and funding shifts are already under way.

However, the impetus for policy change has outpaced the knowledge needed to inform solutions. Fundamental gaps remain in our understanding of the mental health and cognitive needs of U.S. servicemembers returning from Afghanistan and Iraq, the costs of mental health and cognitive conditions, and the care systems available to deliver treatment.

\section{Understanding Invisible Wounds: The Research Challenge}

To begin closing these knowledge gaps, the RAND Corporation conducted a comprehen-

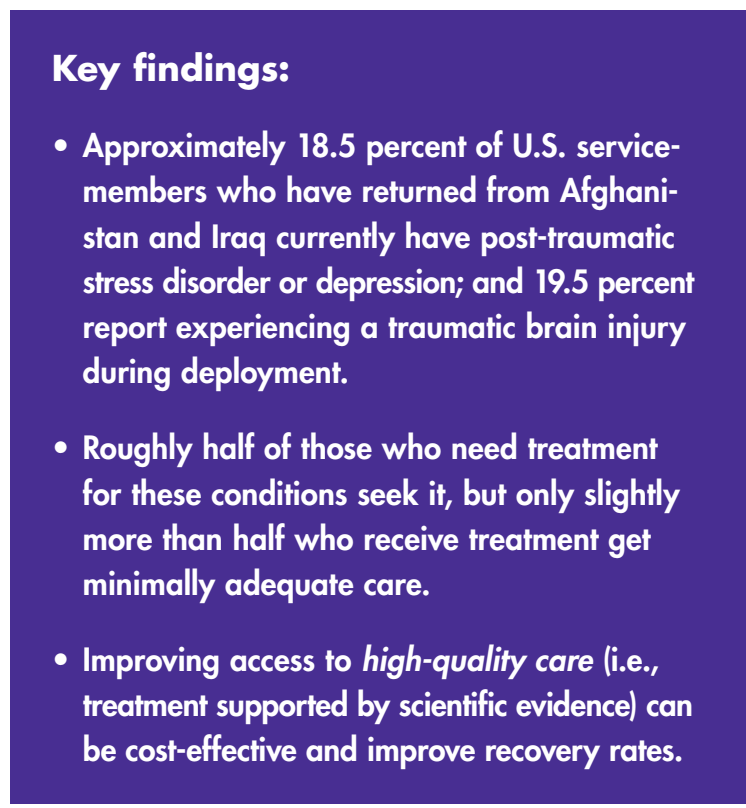

sive study of the mental health and cognitive needs of returning servicemembers and veterans. We focused on three major conditions: posttraumatic stress disorder (PTSD), major depression, and traumatic brain injury (TBI). Unlike physical wounds, these conditions affect mood, thoughts, and behavior and often remain invisible to other servicemembers, family, and society. In addition, symptoms of these conditions, especially PTSD and depression, can have a delayed onset-appearing months after exposure to stress. The effect of traumatic brain injury is still

This Highlight summarizes RAND Center for Military Health Policy Research findings reported in the following publications:

Tanielian T and Jaycox LH, eds., Invisible Wounds of War: Psychological and Cognitive Injuries, Their Consequences, and Services to Assist Recovery, Santa Monica, Calif.: RAND Corporation, MG-720-CCF, 2008, 492 pp., available at http://veterans.rand.org

Tanielian T, Jaycox LH, Schell TL, Marshall GN, Burnam MA, Eibner C, Karney BR, Meredith LS, Ringel JS, Vaiana ME, and the Invisible Wounds Study Team, Invisible Wounds of War: Summary and Recommendations for Addressing Psychological and Cognitive Injuries, Santa Monica, Calif.: RAND Corporation, MG-720/1-CCF, 2008, 64 pp., available at http://veterans.rand.org 
poorly understood, leaving a large gap in understanding how extensive the problem is or how to address it.

The RAND study addressed questions in three areas:

- Prevalence: What are the rates of mental health and cognitive conditions that troops face when returning from deployment to Afghanistan and Iraq?

- The care system: What programs and services exist to meet the health care needs of returning troops with PTSD, major depression, or TBI? Where are the gaps in programs and services? What steps can be taken to close the gaps?

- Costs: What are the societal costs of these conditions? How much would it cost to deliver high-quality care to all who need it?

To answer these questions, a RAND team undertook a series of research tasks. They reviewed existing scientific research on PTSD, depression, and TBI; surveyed a representative sample of current servicemembers and veterans about their current health status, as well as their access to and use of care; and developed an economic model to estimate the costs associated with these conditions. To identify gaps in access to and quality of care, they also assessed the systems of care designed to provide treatment for these conditions and evaluated what is known about the effectiveness of the services being offered. The study was conducted independently from the Department of Defense (DoD) and Department of Veterans Affairs (VA) and is the first of its kind to take a broad, comprehensive view and to consider these problems from a societal perspective.

\section{About One-Third of Returning Servicemembers Report Symptoms of a Mental Health or Cognitive Condition}

The survey of recently returned servicemembers drew from the population of all of those who have been deployed for Operations Enduring Freedom and Iraqi Freedom, regardless of Service branch, component, or unit type. The survey used random digit dialing to reach a representative sample within the targeted locations. All participants were guaranteed confidentiality; the survey data are not linked to any individual's government records. A total of 1,965 individuals responded. Results showed that

- $18.5 \%$ of all returning servicemembers meet criteria for either PTSD or depression (see Figure 1); 14\% of returning servicemembers currently meet criteria for PTSD, and $14 \%$ meet criteria for depression (numbers not shown in Figure 1).

- $19.5 \%$ reported experiencing a probable TBI during deployment (see Figure 1).
- About 7\% meet criteria for a mental health problem and also report a possible TBI.

If these numbers are representative, then of the 1.64 million deployed to date, the study estimates that approximately 300,000 veterans who have returned from Iraq and Afghanistan are currently suffering from PTSD or major depression, and about 320,000 may have experienced TBI during deployment.

\section{Many Services Are Available, but the Care Systems Have Gaps}

What programs and services exist to meet the needs of returning troops with these conditions? What are the gaps? What steps can be taken to close the gaps? To address these questions, the RAND team examined the care systems, identified gaps in care and barriers to care, and assessed how best to fill these gaps.

\section{Access Gaps}

In recent years, the capacity of DoD and the VA to provide health services has increased substantially, particularly in the areas of mental health and TBI. However, gaps in access and quality remain. There is a large gap between the need for mental health services and the use of those services.

\section{Figure 1}

An Estimated 31 Percent of Troops Returning from Iraq and Afghanistan Have a Mental Health Condition or Reported Experiencing a TBI

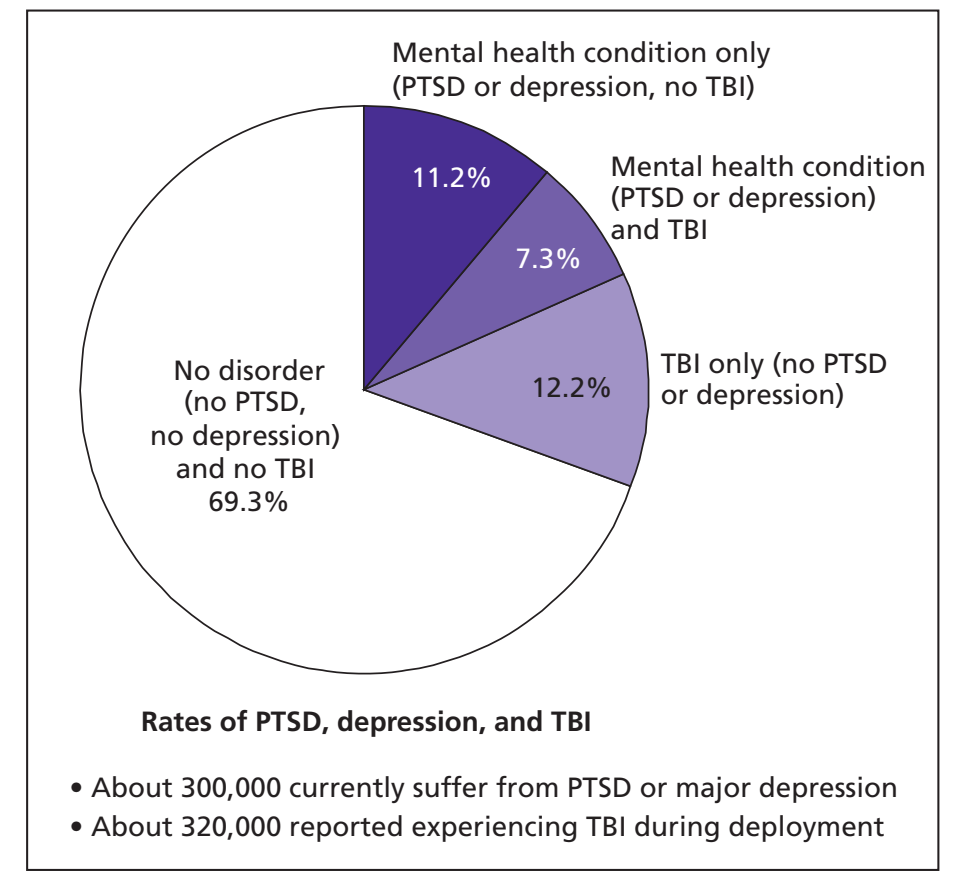


This pattern stems from structural factors, such as the availability of providers, as well as from personal, organizational, and cultural factors. For example, military servicemembers report barriers to seeking care that are associated with fears about the negative consequences of using mental health services. Our survey results (Figure 2) suggest that most of these concerns center on confidentiality and career issues, and so are particularly relevant for those on active duty. Many felt that seeking mental health care might cause career prospects to suffer or coworkers' trust to decline.

However, the VA also faces challenges in providing access to returning servicemembers, who may face long wait times for appointments, particularly in facilities resourced primarily to meet the demands of older veterans. Better projections of the amount and type of demand among the newer veterans are needed to ensure that the VA has appropriate resources to meet potential demand.

These access gaps translate into a substantial unmet need for care. Our survey found that only 53 percent of returning troops who met criteria for PTSD or major depression sought help from a provider for these conditions in the past year. The gap is even larger for those reporting a probable TBI: 57 percent had not been evaluated by a physician for a brain injury.

\section{Quality Gaps}

The study identified gaps in the delivery of quality care. Of those who had PTSD or depression and also sought treatment, only slightly over half received a minimally adequate

\section{Figure 2}

Top-Five Barriers to Seeking Mental Health Care

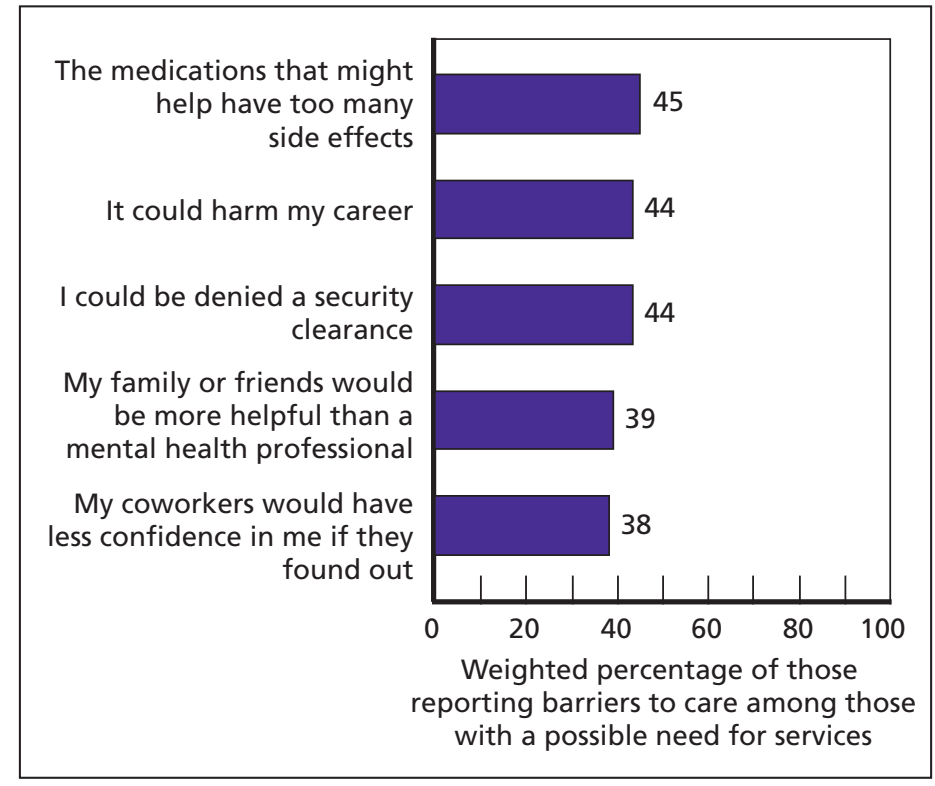

treatment (defined according to the duration and type of treatment received). The number who received high-quality care (treatment supported by scientific evidence) would be even smaller.

The study also identified gaps in the care systems' ability to promote and monitor quality care. In particular, there is room for improvement in the organizational tools and incentives that support delivery of high-quality mental health care. Without these institutional supports, it is not possible to provide oversight to ensure high-quality care, which includes treatment that is evidence-based and also patient-centered, timely, and efficient. DoD and the VA have begun training in evidence-based practices for providers, but these efforts have not yet been integrated into a larger system redesign that values and provides incentives for quality of care.

The VA has been a leader in promoting quality and may provide a promising model for quality improvement of mental health care within DoD. Significant improvements in the quality of care the VA provides for depression have been documented, but efforts to evaluate the quality of care provided within the VA for PTSD remain under way.

\section{Improving Access to High-Quality Care Can Save Money and Improve Outcomes}

Unless treated, PTSD, depression, and TBI can have farreaching and damaging consequences. Individuals afflicted with these conditions face higher risks for other psychological problems and for attempting suicide. They have higher rates of unhealthy behaviors - such as smoking, overeating, and unsafe sex-and higher rates of physical health problems and mortality. Individuals with these conditions also tend to miss more work or report being less productive. These conditions can impair relationships, disrupt marriages, aggravate the difficulties of parenting, and cause problems in children that may extend the consequences of combat trauma across generations. There is also a possible link between these conditions and homelessness. The damaging consequences from lack of treatment or undertreatment suggest that those afflicted, as well as society at large, stand to gain substantially if more have access to effective care.

These consequences can have a high economic toll; however, most attempts to measure the costs of these conditions focus only on medical costs to the government. Yet, direct costs of treatment are only a fraction of the total costs related to mental health and cognitive conditions. Far higher are the long-term individual and societal costs stemming from lost productivity, reduced quality of life, homelessness, domestic violence, the strain on families, and suicide. Delivering effective care and restoring veterans to full mental health have the potential to reduce these longer-term costs significantly. 
Therefore, it is important to consider the direct costs of care in the context of the long-term societal costs of providing inadequate care or no care. The RAND study sought to measure the total costs to society by factoring in treatment costs, losses or gains in productivity, and the costs associated with suicide. In addition, the study calculated the cost effect of getting more people into treatment and improving the quality of care.

Estimates of the cost of PTSD and major depression for two years after deployment range from $\$ 5,900$ to $\$ 25,760$ per case. Applying these per-case estimates to the proportion of the entire population of 1.64 million deployed servicemembers who are currently suffering from PTSD or depression, we estimate that the total societal costs of these conditions range from $\$ 4.0$ to $\$ 6.2$ billion, depending on whether the costs of lives lost to suicide are included.

The cost of TBI is substantially higher per case, but it varies according to the severity of injury. Estimates of the one-year cost of mild TBI range from $\$ 27,260$ to $\$ 32,760$ per case; estimates of moderate to severe TBI costs range between $\$ 268,900$ and $\$ 408,520$ per case.

There is a high level of uncertainty surrounding the cost of TBI, because data are lacking; based on our calculations, the total annual cost associated with the diagnosed cases of TBI (2,776 total cases documented through the middle of 2007) ranges between $\$ 591$ million and $\$ 910$ million.

While the costs of these conditions are high, we know that effective treatments are available for them, particularly for PTSD and depression. However, these evidence-based treatments are not yet available in all treatment settings. Our model also calculated the costs associated with PTSD and major depression if evidence-based treatments were more widely available (not enough is known to estimate the effect of improving quality of care for TBI, because we lack longterm research on effective treatment and recovery rates).

- If 50 percent of those needing care for PTSD and depression received treatment and all care was evidencebased, this larger investment in treatment would result in cost savings overall (see Figure 3).

- If 100 percent of those needing care for PTSD and depression received treatment and all care was evidencebased, there would be even larger cost savings. The cost of depression, PTSD, or co-morbid PTSD and depression could be reduced by as much as $\$ 1.7$ billion, or $\$ 1,063$ per returning veteran. These savings come from increases in productivity, as well as from reductions in the expected number of suicides.

Given these estimates, evidence-based treatment for PTSD and major depression would pay for itself within
Figure 3

Costs per Case (including medical costs, productivity costs, and costs of lives lost to suicide) That Would Be Saved by Investing More in Evidence-Based Care

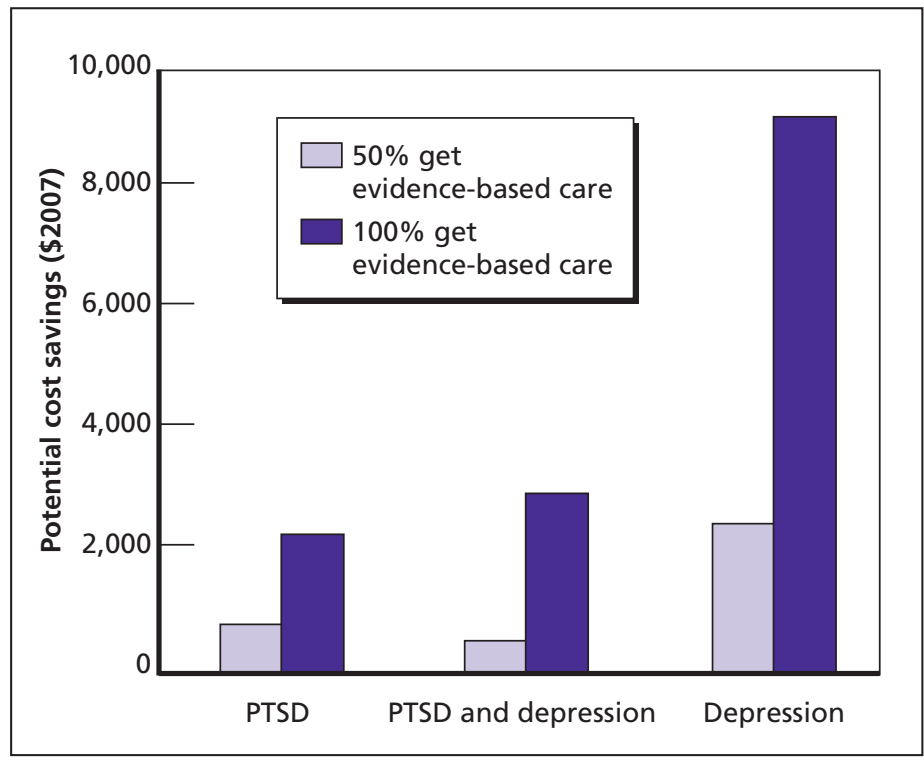

two years. No reliable data are available on the costs related to substance abuse, homelessness, family strain, and other indirect consequences of mental health conditions. If these costs were included, savings resulting from effective treatment would be higher.

These results suggest that investing in evidence-based treatment makes sense both to society and to DoD as an employer. Remission and recovery rates would increase, as would retention, work productivity, and readiness of servicemembers and veterans.

\section{Recommendations and Conclusions}

Looking across all the dimensions of our analysis, we offer four main recommendations for improving the understanding and treatment of PTSD, major depression, and TBI among military veterans:

- Increase and improve the capacity of the mental health care system to deliver evidence-based care. There is substantial unmet need among returning servicemembers for care of PTSD and major depression. DoD, the VA, and providers in the civilian sector need greater capacity to provide treatment, which will require new programs to recruit and train more providers throughout the U.S. health care system.

- Change policies to encourage more servicemembers and veterans to seek needed care. Many who need care are reluctant to seek it. Servicemembers and veterans need ways to obtain confidential services without fear of adverse consequences. 
- Deliver evidence-based care in all settings. Providers in all settings should be trained and required to deliver evidence-based care. This change will require implementing systems to ensure sustained quality and coordination of care and to aid quality improvement across all settings in which servicemembers and veterans are served.

- Invest in research to close knowledge gaps and plan effectively. Medical science would benefit from a deeper understanding of how these conditions evolve over time among veterans as well as of the effect of treatment and rehabilitation on outcomes. The United States needs a national strategy to support an aggressive research agenda across all medical service sectors for this population.
Meeting the health care needs of returning troops who suffer from PTSD, depression, and TBI will be challenging. The prevalence of these conditions is high and may grow as the conflicts in Afghanistan and Iraq continue. The systems of care for meeting these needs have been improved, but critical gaps remain. Without effective treatment, these conditions carry significant long-term costs and negative consequences.

Ultimately, this issue reaches beyond $\mathrm{DoD}$ and the VA into the general U.S. health care system and society at large. Many veterans seek care through private employer-sponsored health plans and in the public sector. The broader health care system must adapt to the needs of this population if the United States is to meet its obligations to military veterans now and in the future. 

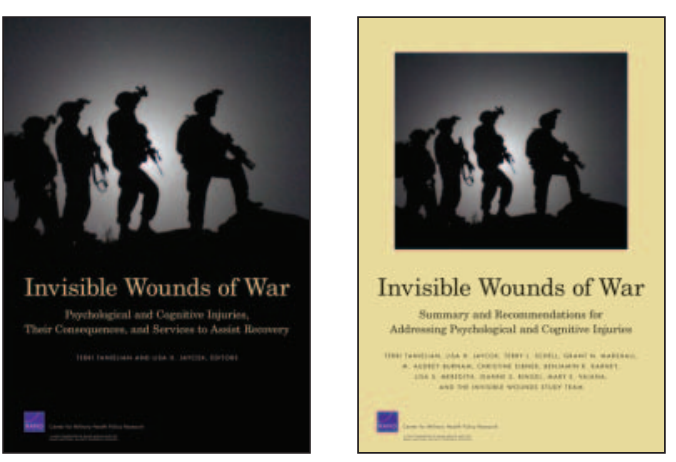

Abstracts of all RAND Health publications and full text of many research documents can be found on the RAND Health Web site at www.rand.org/health. The RAND Corporation is a nonprofit research organization providing objective analysis and effective solutions that address the challenges facing the public and private sectors around the world. RAND's publications do not necessarily reflect the opinions of its research clients and sponsors. RAND ${ }^{\circledR}$ is a registered trademark.

\section{RAND Offices}

Santa Monica, CA • Washington, DC • Pittsburgh, PA - Jackson, MS / New Orleans, LA • Cambridge, UK • Doha, QA 


\title{
RAND Center for Military Health Policy Research
}

\author{
A JOINT ENDEAVOR OF RAND HEALTH AND THE \\ RAND NATIONAL SECURITY RESEARCH DIVISION
}

THE ARTS

CHILD POLICY

CIVIL JUSTICE

EDUCATION

ENERGY AND ENVIRONMENT

HEALTH AND HEALTH CARE

INTERNATIONAL AFFAIRS

NATIONAL SECURITY

POPULATION AND AGING

PUBLIC SAFETY

SCIENCE AND TECHNOLOGY

SUBSTANCE ABUSE

TERRORISM AND HOMELAND SECURITY

TRANSPORTATION AND

INFRASTRUCTURE

WORKFORCE AND WORKPLACE
This PDF document was made available from www.rand.org as a public service of the RAND Corporation.

This product is part of the RAND Corporation research brief series. RAND research briefs present policy-oriented summaries of individual published, peerreviewed documents or of a body of published work.

The RAND Corporation is a nonprofit research organization providing objective analysis and effective solutions that address the challenges facing the public and private sectors around the world.

\section{Support RAND}

$\underline{\text { Browse Books \& Publications }}$

Make a charitable contribution

\section{For More Information}

\author{
Visit RAND at www.rand.org \\ Explore the RAND Center for Military Health Policy Research \\ View document details
}

Limited Electronic Distribution Rights

This document and trademark $(s)$ contained herein are protected by law as indicated in a notice appearing later in this work. This electronic representation of RAND intellectual property is provided for non-commercial use only. Unauthorized posting of RAND PDFs to a non-RAND Web site is prohibited. RAND PDFs are protected under copyright law. Permission is required from RAND to reproduce, or reuse in another form, any of our research documents for commercial use. For information on reprint and linking permissions, please see RAND Permissions. 